\title{
PARA QUE SERVE A TEORIA DA ALIENAÇÃO? ${ }^{1}$
}

Ramon Peña Castro²

\section{Resumo}

Este texto propõe uma reflexão sobre o significado da teoria da alienação; sua relação com a proliferação de diversas teorizações sociológicas que pretendem explicar o processo de reconstrução da realidade social moderna como representação. $\mathrm{O}$ debate gira em torno da centralidade de fenômenos, mais ou menos novos, que servem de base para teorias como: sociedade do espetáculo, sociedade de consumo, sociedade do conhecimento, sociedade computacional $\mathrm{Na}$ conclusão sugerimos retomar a critica do fetichismo do mercado, juntos aos mitos da empregabilidade e do empreendedorismo, propiciadores de comportamentos passivos e autoalienação ignorada.

Palavras-chave: Alienação; Empregabilidade; Empreendedorismo; Sociedade de consumo; Sociedade do espetáculo; Sociedade do conhecimento; Sociedade digital.

\section{Abstract}

This text proposes a reflection on the meaning of the theory of alienation; its relationship with the proliferation of various sociological theories aiming to explain the process of reconstruction of modern social reality. The debate relies on some new phenomena, which have been the bases for theories like those of the spectacle society, the consumer society, the knowledge society and the computational society. Summarizing, we suggest the adoption of a critical perspective on the idea of market fetishism together with some myths on employability and entrepreneurship, which may lead to passive behaviors and self-alienation.

Keywords: Alienation; Employability; Entrepreneurship; Spectacle society; Consumer society; Knowledge; Computational society.

\section{Introdução}

Os anos 70 marcaram o fim do capitalismo "com rosto humano", comprovando-se que o chamado Estado de Bem-estar foi uma mera contingência histórica e não fruto de insondáveis leis naturais.

A sucessiva ofensiva neoliberal cada dia mais reacionária não pode ser considerada como definitiva. É uma etapa que situa em um novo patamar

\footnotetext{
${ }^{1}$ Foi preservada a forma de reprodução, pelo autor, de sua intervenção no III Intercrítica (nota dos editores).

2 Escola Politécnica de Saúde Joaquim Venâncio - FIOCRUZ.

TrabalhoNecessario - www.uff.br/trabalhonecessario; Ano 14, № 25/2016
} 
barreiras que as classes trabalhadoras têm que superar para conquistar um futuro de "liberdade, igualdade e fraternidade".

Um dos traços, talvez o principal, da presente etapa histórica consiste na mudança do espaço de disputa da Hegemonia (domínio+consenso). Nas etapas históricas precedentes a FABRICA foi -segundo Gramsci- o centro de construção de hegemonia e contra-hegemonia. Hoje, esse centro parece ter-se deslocado para o MERCADO. Um ente ${ }^{3}$ abstrato e onimodo, usado e abusado para apagar a noção de CAPITALISMO.

Esta mudança de cenário da hegemonia manifesta-se em uma serie de modismos ideológicos, tais como sociedade de consumo, sociedade do espetáculo. Sociedade informática, sociedade do conhecimento, empreendedorismo, "Uber-ismo", ,etc..

Para começar a entender as causas materias e espirituais do eclipse das culturas de resistência revolucionaria anticapitalista, esta intervenção propõe uma reflexão sobre a origem e natureza desse novo hedonismo de massas, chamado consumismo com sua adição tecnológica.

Com indissimulada ortodoxia consideramos essas mistificações ${ }^{5}$ incompatíveis com a crítica marxista de capitalismo, ou mais exatamente com a dialética materialista ou "estudo concreto da realidade concreta" (Lênin). Para melhor entender o que ocorre abordamos a seguir o conceito marxista da alienação do trabalho assalariado.

\section{Aproximação a Teoria marxista da Alienação}

A teoria marxista da alienação representa "uma genealogia da consciência", uma "fundamentação materialista do processo de construção social da realidade como representação" (Fernandez Enguita ${ }^{6}$ ). Em outras palavras, a teoria da alienação pretende explicar como a concepção de mundo

\footnotetext{
${ }^{3}$ Ente= aquilo que existe, coisa, substancia, ser..[dicionário Aurelio]

${ }^{4}$ UBER =arquétipo de relação triangular que invisibiliza a dominação econômica "atípica e descolada do direito trabalhista" e da tributação empresarial. Ciberpoder que oculta as novas degradações do trabalho de mercado. [Cf. J.Dirringer. "El derecho social, ante la prueba de la uberización" . IN HTTP://vientosur.info/spip.php?article11695]

5 Segundo Roland Barthes (Mytologies,1957) o MITO funciona como uma palavra que naturaliza o fato social esvaziando-o do seu conteúdo histórico.

${ }^{6}$ Fernández Enguita, Mariano. Trabajo, escuela e ideología. Marx y la crítica de la educación. Madrid, Akal, 1985:144
}

TrabalhoNecessario - www.uff.br/trabalhonecessario; Ano 14, № 25/2016 
e de homem, própria a cada cultura e de cada grupo social e também a cada individuo concreto, surge 'espontaneamente' a partir da experiência de determinadas condições materiais de existência humana, da produção e reprodução especifica dessa existência.

A teoria da alienação tem sido objeto de longos debates, desde o século XIX até hoje. A primeira exposição filosófica da alienação foi feita, em 1807, por George W.F. Hegel. Em sua Fenomenologia do espírito, a alienação constitui a categoria central do mundo moderno; através da qual o espírito se objetiva, em todos os seus níveis e manifestações, através do estranhamento universal de Deus (Idéia ou Espírito Absoluto).

Para Hegel toda alienação pode ser superada na medida em que a Idéia desenvolva seu autoconhecimento até tornar-se absoluto, pressupondo que esse desenvolvimento acompanha a crescente complexidade social e espiritual da historia do ser humano, representada pela filosofia idealista moderna.

Para Feuerbach 7 , a idéia hegeliana de Deus não passa de ser uma alienação da essência humana, projetada num céu imaginário; elevada ao absoluto e descolada, assim, da realidade humana que é a sua fonte real. Contra o que ele considera teologia hegeliana, Feurbach propõe uma antropologia.

Por sua vez, Marx considera que a idéia de homem de Feuerbach é insuficiente porque também representa outra abstração. Criticando esta visão, ele (Marx) concentra sua atenção na realidade material do homem, afirmando que a alienação surge nesse plano material. Mediante a categoria de trabalho alienado ${ }^{8}$. Marx desloca a problemática da esfera filosófica para a econômica. Concretamente no campo econômico, onde a mercantilização da força ou capacidades humanas de trabalho, isola e submete os trabalhadores (despossuídos de meios de produção e de vida), ao poder de decisão de capital, tanto no processo de produção como na apropriação do produto do trabalho assalariado. Por conta disso, o trabalho (processo de consumo da mercadoria força de trabalho) junto ao seu resultado (produto-mercadoria), tornam-se forças estranhas ou alienadas que submetem ao ser humano assalariado, impedindo a plena expressão da sua humanidade.

\footnotetext{
${ }^{7}$ Feuernach, L. La esencia del cristianismo. (Salamanca, Sígueme, 1975)

${ }^{8}$ Marx, K. Manuscritos econômico-filosóficos de 1844. (texto inédito recuperado em 1932)

TrabalhoNecessario - www.uff.br/trabalhonecessario; Ano 14, № 25/2016
} 
Nos seus Manuscritos de 1844, Marx salienta quatro aspectos principais da alienação:

1) o homem alienado da natureza (no entanto o trabalho é uma relação com a matéria para transformá-la);

2) o homem está estranhado de si mesmo, da sua práxis (da sua própria atividade e intencionalidade);

3) o homem está alheio ao seu "ser genérico" (seu ser enquanto membro do gênero humano) $e$

4) o homem está estranhado do homem (dos outros seres humanos).

Ao atribuir um conteúdo econômico (materialista e histórico) à alienação, Marx transcende o nível mais abstrato da teoria para penetrar no mais concreto: a luta social (econômica, política e ideológica). Nível que permite conceber e defender a superação do trabalho assalariado (alienado e explorado) como um processo histórico (social, político e ideológico) de transformação revolucionaria, socialista, do modo de produção capitalista.

O fenômeno da alienação está profundamente relacionado com a "coisificação" do ser humano, convertido de fato em instrumento do capital, proprietário e gestor das condições materiais e espirituais de produção, fenômeno inerente à sociedade capitalista onde tudo reveste a forma de mercadoria.

O fenômeno da alienação será demonstrado por Marx no inicio de "O Capital" (livro I, cap.1, item 4), onde aborda "o fetichismo da mercadoria".

Com um pouco de paciência pode-se verificar que a critica da alienação está presente em todo O CAPITAL, em todo seu sistema categorial de Marx: Dinheiro, Capital, Salário, Lucro, Renda fundiária, Juro, etc.

A alienação do trabalho no capitalismo subsume e amplia anteriores dominações, tornando-se totalitária ou ampliada a todos os aspectos econômicos, políticos e éticos.

Em razão disso, o sistema capitalista somente conhece (e reconhece) o trabalhador como força de trabalho mercantilizada, como simples, "recurso" ou "fator" produtivo, utilizado (consumido) no trabalho, mas reproduzido fora do trabalho, conforme as exigências da sua própria reprodução.

Condição necessária desta reprodução é a existência de exército assalariado flexível (de ativos e reservistas) ou "classe em si" que apresenta TrabalhoNecessario - www.uff.br/trabalhonecessario; Ano 14, № 25/2016 
três dimensões, analisadas com auxilio de três conceitos: Exploração, Dominação e Alienação.

1. O trabalhador assalariado é explorado, ou seja, extorquido do "trabalho excedente," e do "produto excedente", através de diferentes procedimentos que se traduzem na mais-valia (processo analisado por Marx, no Capital, livro I, capítulos 5-16).

2. O trabalhador está dominado, subsumido no capital, privado, portanto, de capacidade de decisão na práxis social, nas mediações sociais fundamentais: repartição do produto social; comunicação social, produção simbólica e todo tipo de poder de decisão social, poder usurpado pelo bloco político das classes dominantes.

3. O trabalhador assalariado é alienado, o que significa que o principal produtor da base material da vida social, perde qualquer controle sobre a sua obra que se transforma em poder estranho que o esmaga e despoja da sua humanidade, através das diferentes formas e graus de miséria física e social (moral e intelectual) que o capitalismo impõe a "classe em si".

No capitalismo contemporâneo há que considerar especialmente a pressão crescente do desemprego e da precarização institucionalizada, resultado disso é que os trabalhadores encontram-se alienados, não apenas como trabalhadores em ativo (empregados), mas igualmente como desempregados, vistos (pelos "ativos") como concorrentes que ameaçam sua precária estabilidade.

Essa ameaça permanente de perder o emprego, num contexto geral de precarização e degradação social ("marginalização"), longe de servir para radicalizar as lutas políticas por direitos coletivos (em particular pela transformação das relações de produção), parecem ter consolidado a subordinação do trabalho ao capital.

Uma das consequências dramáticas dessa iniquidade (terrorismo legitimado) é a crescente desconfiança nos sindicatos e partidos que se atribuem a representação dos trabalhadores; desconfiança incentivada pelos "managers" (gestores) empresariais e seus aparatos ideológicos. Tudo isso contribui a queda da qualidade dos empregos e a erosão da sociabilidade e das solidariedades de classe.

TrabalhoNecessario - www.uff.br/trabalhonecessario; Ano 14, № 25/2016 
O desejo do trabalhador desempregado de recuperar um emprego (precarizado), que percebe como parte da sua humanidade, consolida um sistema que desumaniza tanto aos empregados como aos desempregados. Em outras palavras reforça a alienação.

O estigma do desemprego é interiorizado pelo sujeito que supervaloriza o que the falta e menospreza o que tem (as capacidades físicas e intelectuais próprias de todo ser humano).

O tempo de vida disponibilizado pelo desemprego é vivido como privação, como excedente penoso da ausência de tempo de trabalho.

$\mathrm{Na}$ cultura do trabalho assalariado (alienado), o trabalhador ativo e o trabalhador desempregado estão subsumidos (presos) pela centralidade do trabalho como dimensão identitaria.

Do mesmo modo que os desempregados se sentem expropriados da sua "humanidade" que associam ao trabalho, os trabalhadores empregados não deixam de sentir-se negados a si mesmos no processo de trabalho alienado.

Assim, se os primeiros sentem um déficit de identidade, os segundos sentem excesso de frustração.

Por conta disso, verificamos que não há apenas problemas de desemprego, mas também de subemprego e hiper-trabalho, pois em todas essas situações observamos divergências mais o menos profundas entre 0 trabalho e as necessidades vitais.

Por sua vez, os trabalhadores classificados como "qualificados" (profissionais ou intelectuais) também estão estranhados e até contrapostos a aqueles mais desvalidos, reduzidos ao "trabalho manual", cuja qualificação sempre existe ainda que não seja reconhecida. (Reconhecimento este que é uma arma de uso exclusivo do empregador). Outro aspecto marcadamente discriminador é o dos trabalhos chamados "do lar" (trabalhos domésticos), necessários para alimentar, vestir, cuidar da higiene, da educação e da saúde de crianças, doentes ou idosos, exercidos sem remuneração, representando 
uma sobrecarga de trabalho, principalmente para as mulheres sujeitas além do mais a prejuízos patriarcais e machistas ${ }^{9}$.

\section{Sobre publicidade, consumo e tecnologísmos como espaços de alienação}

É amplamente conhecido e reconhecido o crescente poder dos meios de persuasão e comunicação massiva (baseados nas TIC) para formatar opinião pública (o que justifica a identificação entre "opinião pública" e "opinião publicada").

Esse poder consolidou-se especialmente nas últimas três décadas (a partir dos anos de 1980), coincidindo com a instauração do neoliberalismo, nova fase da dominação capitalista demolidora dos direitos sócias dos trabalhadores.

A concentração do capital e a centralização do poder num número reduzido de grandes corporações transnacionais interligadas ${ }^{10}$, junto ao desenvolvimento tecnológico das comunicações que cobrem o globo terrestre com uma densa rede de sistemas informáticos, controlados e operados por um reduzido numero de transnacionais da "informação" e do "entretenimento".

Através desta rede, os poderes hegemônicos impõem ao mundo sua cosmovisão, a qual funciona como uma poderosa arma de domesticação e alienação das grandes maiorias.

Trata-se de um sistema de persuasão e domínio totalitário que faz com que os dominados, os subalternos pensem e vejam o mundo com os olhos dos dominadores.

O que hoje nos tentam impor sob o ambíguo rótulo de mercado é a submissão inapelável, a ideia da impossível organização e resistência frontal do mundo do trabalho.

Essa pretensão fatalista tem a ver com a fragmentação social. Se a primeira conquista e condição de implementação do capitalismo foi a

\footnotetext{
${ }^{9}$ Sugestões bibliográficas: Silvia Federici (entrevista) "Ni el Estado ni el mercado contribuyen a la reproducción" http://www.vientosur.info/spip.php?article8855 e (da mesma autora) "Uma crise reprodutiva permanente". <http://www.vientosur.info. junio de 2013

${ }^{10} \mathrm{~A}$ máquina da iniquidade transfigura todo o planeta. Os 63.000 indivíduos (18.000 em Ásia, 17.000 em EE.UU.e 14.000 em Europa) com patrimônio superior a 100 milhões de dólares, totalizam uma fortuna de 39,9 trilhões de dólares. Para ter idéia do que isso representa cabe reparar que em 2011 o PIB mundial foi de 70 trilhões de dólares (cf. Serge Halimi. "Inegalités, démocratie, souveranite". Le Monde Diplomatique. Mai 2013, p.8).
}

TrabalhoNecessario - www.uff.br/trabalhonecessario; Ano 14, № 25/2016 
expropriação dos meios de produção e de vida dos camponeses e artesões e sua transformação em mercadoria força de trabalho, a segunda conquista está sendo a individualização extrema, a imposição de formas de vida tão mercantilizadas (coisificadas) que naturalizam a alienação e invisibilizam a barbárie capitalista.

Como salienta Marx, as estruturas de exploração e alienação somente são perceptíveis desde uma ótica coletiva, desde uma visão da totalidade social (econômica e política).

\section{Algumas questões para debate}

De que forma os meios de persuasão ou mídia contribuem para a reprodução ampliada da alienação dos indivíduos e grupos sociais?

Podemos considerar a publicidade como a primeira forma que, inundando o espaço visual, auditivo e cibernético, sobretudo, a partir da segunda metade do século $X X$, formata a visão de mundo e/ou narcotiza as maiorias subalternas?.

Gostaríamos de lembrar alguns fatos históricos. A mais de meio século que o norte-americano Vance Packard ${ }^{11}$ dissertou, através de uma serie de ensaios publicitários, sobre as estruturas funcionais da publicidade ("estratégias de persuasão oculta”, "domínio do público pelo subconsciente", "sugestão subliminar" etc.), assim como sobre as estratégias de promoção do consumo desmedido.

Nas décadas seguintes, outros autores desenvolveram essas reflexões ${ }^{12}$. Por exemplo, Guy Debord, em seu livro A sociedade do espetáculo, introduziu a noção a produção imaterial ${ }^{13}$ na teoria da alienação, retomando a tese de Max Horkheimer e Theodor Adorno, exposta na sua Dialética do Iluminismo, segundo a qual o capitalismo moderno também subsume o divertimento (lazer) na esfera da produção de consenso.

Debord afirma que no capitalismo desenvolvido o operário "é tratado, aparentemente, como verdadeira pessoa, com cortesia, porque a economia política objetiva colonizar o lazer e a humanidade do trabalhador".

\footnotetext{
${ }^{11}$ Vance Packard. Nova técnica de convencer e A sociedade nua (Editora Ibrasa).

12 Guy Debord. (1967) A sociedade do espetáculo; Jean Braudrillard (1970) A sociedade de consumo.

${ }^{13}$ Antecipando-se, portanto, a André Gorz e Toni Negri.

TrabalhoNecessario - www.uff.br/trabalhonecessario; Ano 14, № 25/2016
} 
Daí a denominação "Sociedade do espetáculo". "Na sociedade atual escreve Debord - o espetáculo corresponde a uma fabricação concreta da alienação", alienação que segundo ele é aceita com prazer pelos indivíduos que enganchados ao novo ópio do povo (o consumo)" e "identificados com as imagens dominantes", renunciam cada vez mais a construir seus desejos e existências livres.

Jean Braudrillard também utiliza o conceito de alienação para definir as mudanças sociais ocorridas no capitalismo tardio, identificando o consumo como esfera principal da sociedade moderna.

A era da expansão do consumo, quando a publicidade e as enquetes geram necessidades fictícias, ter-se-ia transformado, segundo Braudillard, "na era da alienação radical quando a lógica da mercadoria se universaliza". De tal modo que não apenas regula os processos de trabalho e de produção material, se não também toda a cultura, a sexualidade e todas as relações humanas. Tudo é vendido como espetáculo, como evocação, provocação, orquestração de imagens, de símbolos e modelos consumíveis.

Estas reflexões tem o defeito de reduzir a alienação a um fenômeno individual; inerente ao ser humano individual e não as relações sociais radicalmente mercantilizadas. Enfatizam a propensão dos indivíduos à se adaptar à ordem existente, subestimando, ao mesmo tempo, as ações coletivas de resistência e a procura de transformação social.

Em outras palavras, as mencionadas interpretações acabam por marginar e omitir os fatores histórico-sociais, determinantes da alienação, optando por uma espécie de hiper-psicologização da analise do conceito alienação, presente numa serie de interpretações sociológicas e psicológicas.

Face ao elitismo de muitos discursos intelectualistas que associam a inocultável regressão social do "mundo do trabalho" a fenômenos de massificação e "empoderamento" dos subalternos, cabe insistir na analise das numerosas evidencias empíricas que demonstram que essa regressão ("mutação antropológica"14) decorre da ação direta das oligarquias políticoempresariais ou seja, das relações de dominação existentes.

\footnotetext{
14 Joaquim Miras. Sujeto de la historia y desastre cultural..La transformación antropologica; http://www.rebelion.org/noticia. $p h p ? i d=91211$. Idem: noiticia.php?id=91211>
}

TrabalhoNecessario - www.uff.br/trabalhonecessario; Ano 14, № 25/2016 
São essas oligarquias que decidem a vida das grandes maiorias em proveito próprio. Elas comandam o espetáculo ("passem circenses") da chamada sociedade de consumo, impondo seu credo ideológico através de aparelhos de persuasão e repressão adequados à correlação da luta de classes.

Com a particularidade de que os produtos culturais e de lazer, unidos aos artefatos de moda que configuram a sociedade de consumo, não apenas divertem e adormecem, senão que incentivam desejos e procura de lucros e, com isso, um individualismo egoísta, associado a uma ideologia econômica servil e um espírito cego de competitividade impiedosa.

Um exemplo, muito atual e massivo, é o dos "proprietários" de imóveis mediante hipotecas que nos países centrais e periféricos golpeados pelo crise atual com o desemprego e precarização generalizada. Hoje afundados no desespero e frustrados no seu sonho de "ascensão social" e incorporação à classe dos proprietários.

Partindo de este exemplo parece oportuno repensar (ou divagar) sobre o sentido atual das noções de Marx-Engels "classe em si", "classe para si" ou "classe contra si" [advertindo que esta ultima noção está mais próxima do estilo sarcástico de Charles Chaplin ou de Gruncho Marx].

O predomínio do atual discurso economicista é tão absoluto e reducionista que aniquila a possibilidade de reconsiderar as prioridades da sociedade e, portanto a sua transformação, contribuindo para o desarme político e ideológico dos dominados.

Em definitivo, o grande embuste de nossa época consiste em fazer acreditar que as atuais democracias de fachada trabalham a favor de uma sociedade de indivíduos livres e iguais, quando na realidade promovem valores e relações sociais cujo resultado é totalmente oposto a isso.

São justamente os falsos valores mercantis, as relações opressoras e o terrorismo do mercado globalizado, as causas determinantes dos comportamentos passivos e da alienação ignorada.

O medo a perder o emprego, de descer de status ou de ser discriminado é o que gera em muitos indivíduos isolados autoinculpação e autoalienação, sem necessidade de repressões explicitas. 
Para terminar, pensemos na função mistificadora de noções como "empregabilidade", "modelo de competências", "gestão por metas", "avaliações" e outras engenhocas das chamadas ciências gerenciais ${ }^{15}$.

\section{Referências Bibliográficas}

Braudrillard, J. A sociedade de consumo. Lisboa, Edições 70, 1970.

Debord, G. A sociedade do espetáculo. Disponível em http://www.ebooksbrasil.org/adobeebook/socespetaculo.pdf, acesso agosto de 2016

Dejours, C. A banalização da injustiça social. Rio de Janeiro: FGV, 2007 . O fator humano. Rio de Janeiro, FGV, 2005

Dejours C, Bègue F. Suicídio e trabalho: o que fazer? Brasília: Paralelo 15; 2010

Enguita, F. Trabajo, escuela e ideología. Marx y la crítica de la educación. Madrid: Akal, 1985

Federici, S. (entrevista) "Ni el Estado ni el mercado contribuyen a la reproducción". Disponível em: http://www.vientosur.info/spip.php?article8855, acesso agosto de 2016.

Uma crise reprodutiva permanente". Disponível em: <http://www.vientosur.info>. junio de 2013, acesso agosto de 2016

Feuerbach, L. La esencia del cristianismo. Salamanca: Sígueme, 1975

Halimi, S. Inegalités, démocratie, souveranite. Le Monde Diplomatique. Mai 2013

Marx. K. Manuscritos econômico-filosóficos de 1844. (texto inédito recuperado em 1932)

O Capital: Livro 1 - O processo de produção do Capital. Rio de Janeiro: Civilização Brasileira, 1985.

Miras, Joaquim. Sujeto de la historia y desastre cultural. La transformación antropologica; http://www.rebelion.org/noticia.php?id=91211. Idem: noiticia. php?id=91211>, acesso em agosto de 2016

\footnotetext{
${ }^{15}$ Vide Christophe Dejours. A banalização da injustiça social. Rio de Janeiro: FGV, 2007. Do mesmo autor: O fator humano. Rio de Janeiro, FGV, 2005 e Suicídio e trabalho: o que fazer? Dejours C, Bègue F. Brasília: Paralelo 15; 2010.
}

TrabalhoNecessario - www.uff.br/trabalhonecessario; Ano 14, № 25/2016 
Packard, V. Nova técnica de convencer. SP, IBRASA, 1959

A sociedade nua (Editora Ibrasa). São Paulo, Ibrasa, 1966

TrabalhoNecessario - www.uff.br/trabalhonecessario; Ano 14, № 25/2016 